\title{
Projected impact of polypill use among US adults: medication use, cardiovascular risk reduction and side effects
}

\author{
Paul Muntner, Devin Mann, Rachel P Wildman, Daichi Shimbo, Valentin Fuster, and Mark \\ Woodward \\ Department of Epidemiology and Medicine (PM), University of Alabama at Birmingham, \\ Birmingham, AL. Department of Medicine (DM, MW), and the Zena and Michael A. Wiener \\ Cardiovascular Institute and Marie-Josée and Henry R. Kravis Center for Cardiovascular Health \\ (VF), Mount Sinai School of Medicine, New York, New York. Department of Epidemiology and \\ Population Health (RPW), Albert Einstein College of Medicine, Bronx, NY. Department of \\ Medicine (DS), Columbia University, New York, NY
}

\begin{abstract}
Background-Polypills which include multiple medications for reducing cardiovascular disease (CVD) risk in a single pill have been proposed for population-wide use. The number of US adults eligible for polypills and potential benefits are unknown.

Methods-The National Health and Nutrition Examination Survey 2003-2004 and 2007-2008 were analyzed to estimate treatment rates for medications proposed for inclusion in polypills (aspirin, statin, an ACE-inhibitor, and a thiazide-type diuretic for those without, a beta-blocker for those with, a history of myocardial infarction) among US adults. The number of coronary heart disease (CHD) and stroke events potentially prevented through polypill use was projected by published meta-analyses and three large population-based cohort studies. Two polypill eligibility criteria were analyzed (1) US adults $\geq 55$ years and (2) US adults with a history of CVD.
\end{abstract}

Results-There are 67.6 million US adults $\geq 55$ years and 15.4 million US adults with a history of CVD and, thus, eligible for polypills using the two outlined criteria. In 2007-2008, 37.3\% of US adults $\geq 55$ years and $57.0 \%$ of those with a history of CVD were taking statins. Use of other polypill medications was also low. Polypill use by US adults age $\geq 55$ years is projected to potentially prevent 3.2 million CHD events and 1.7 million strokes over 10 years. Amongst those with a history of CVD, the potential to prevent of 0.9 million CHD events and 0.5 million strokes is projected.

Conclusions-Polypills have the potential to lower CVD incidence substantially among US adults.

In 2001, participants in a meeting of the World Health Organization and Wellcome Trust
discussed the development of fixed dose combination medications for the secondary
prevention of cardiovascular disease (CVD)(1). In 2003, Wald and Law proposed a
"Polypill" which would include multiple pharmacological therapies aimed at reducing CVD

() 2011 Mosby, Inc. All rights reserved.

Address correspondence and reprint requests to: Paul Muntner, Department of Epidemiology, University of Alabama at Birmingham, 1655 University Boulevard, Suite 220, Birmingham, AL 35294, Tel : (205) 975-8077, pmuntner@uab.edu.

Disclosures: The authors have no potential conflicts of interest to report.

Publisher's Disclaimer: This is a PDF file of an unedited manuscript that has been accepted for publication. As a service to our customers we are providing this early version of the manuscript. The manuscript will undergo copyediting, typesetting, and review of the resulting proof before it is published in its final citable form. Please note that during the production process errors may be discovered which could affect the content, and all legal disclaimers that apply to the journal pertain. 
risk by attacking several biological processes simultaneously(2). Rather than limiting the polypill to secondary prevention, it has been proposed as a public health intervention for use by all adults $\geq 55$ years of age regardless of, and with little to no monitoring of, risk factor levels. Using such a population-based approach, polypills have been projected to result in reductions in coronary heart disease (CHD) and stroke incidence as high as $88 \%$ and $80 \%$, respectively(2). Multiple different polypill formulations have been developed over the past 5 years, with randomized controlled trials of their benefit currently underway(3-5).

The purpose of the current analysis was to determine the number of US adults eligible for polypills aimed at reducing CVD risk. As the criteria for polypill eligibility are not fixed, we investigated the number of eligible US adults using two approaches: (1) a population-based approach as recommended by Wald and Law in which all US adults age $\geq 55$ years would be recommended polypills, and (2) a high risk approach wherein those with a history of CVD would be recommended a polypill. Additionally, we calculated the proportion of each of these populations currently taking cardio-protective medications including aspirin, antihypertensive medications, and statins and projected the number of CHD and stroke events that could be prevented through the administration of polypills in these populations.

\section{Methods}

\section{Study Population}

The National Health and Nutrition Examination Survey (NHANES) is conducted in two year cycles with each cycle including representative samples of the non-institutionalized civilian population of the US(6). The main analyses included 2,554 participants, 20 years and older, who completed an in-home interview and a medical evaluation as part of NHANES 2007-2008. Analyses including LDL-cholesterol and fasting plasma glucose values were based on 977 participants whose medical evaluation was conducted after an overnight fast of 9 or more hours. While NHANES 2007-2008 included a pill bottle review to capture prescription medication use, daily aspirin use was not collected in this survey cycle. Thus, daily aspirin use was obtained from NHANES 2003-2004 $(n=2,112)$.

\section{Data Collection}

Questionnaires were used to record demographics, cigarette smoking, personal and family history of CHD, and history of diabetes. Diabetes was defined as a self-report of a previous diagnosis while not pregnant and/or current antidiabetes medication use and/or fasting plasma glucose $\geq 126 \mathrm{mg} / \mathrm{dL}$. Blood pressure was measured three times and averaged(7). Hypertension was defined as a systolic blood pressure $\geq 140 \mathrm{mmHg}$ and/or diastolic blood pressure $\geq 90 \mathrm{mmHg}$ and/or current antihypertensive medication use. Current use of antihypertensive medication classes and statins was determined through pill bottle review by trained study staff. Aspirin use was ascertained via standardized questions and flash cards listing different types of analgesic medications. Participants with LDL-cholesterol exceeding cut-points defined in the National Cholesterol Education Panel Adult Treatment Panel III guidelines $(\geq 160 \mathrm{mg} / \mathrm{dL}$ for adults without CHD and $0-1$ CHD risk factors, $\geq 130 \mathrm{mg} / \mathrm{dL}$ for adults without CHD and $\geq 2$ CHD risk factors, and $\geq 70 \mathrm{mg} / \mathrm{dL}$ for adults with CHD or a CHD risk equivalent) or taking statins were considered to have high LDL-cholesterol(8).

Eligible populations-Two populations were evaluated for potential polypill use. The first population, included all US adults $\geq 55$ years of age. The second population included individuals with a history of CVD defined as a self-report of a prior diagnosis of myocardial infarction, CHD, or stroke by a healthcare professional. 
Treatment recommendations-Current treatment recommendations for aspirin, antihypertensive medications and statins were based on published guidelines. Aspirin therapy is recommended for adults with a history of CVD or a 10-year risk of CHD $\geq$ 10\%(9). Antihypertensive medications and statins are recommended for adults with hypertension and high LDL-cholesterol, respectively. Beta-blockers are recommended for adults with a history of myocardial infarction(10).

Polypill ingredients-Two polypill formulations which are currently being evaluated in randomized controlled trials were investigated for the current analysis(11). Polypill one was assumed to contain aspirin, an ACE-inhibitor, a thiazide-type diuretic, and a statin, and was deemed applicable for the general population without a history of myocardial infarction. Polypill two was assumed to contain aspirin, an ACE-inhibitor, a beta-blocker, and a statin, and was deemed applicable for those with a history of myocardial infarction.

Projected CVD risk reduction with polypill use-The expected reduction in CHD and stroke incidence due to medication use was obtained from published meta-analyses. For aspirin, the risk reduction benefits $(95 \% \mathrm{CI})$ for individuals without and with a history of CVD were $18 \%(10 \%, 25 \%)$ and $20 \%(12 \%, 27 \%)$, respectively, for CHD and 5\% (-17\%, $+10 \%)$ and $19 \%(4 \%, 32 \%)$, respectively, for stroke. The CHD and stroke risk reduction benefits were $26 \%(23 \%, 29 \%)$ and $16 \%(95 \%$ CI: $9 \%, 21 \%)$ for statins, $20 \%(12 \%, 27 \%)$ and $28 \%(19 \%, 36 \%)$ for ACE-inhibitors, $21 \%(8 \%, 31 \%)$ and $29 \%(19 \%, 37 \%)$ for lowdose diuretics, and $7 \%(0 \%, 19 \%)$ and $20 \%(4 \%, 34 \%)$ for beta-blockers(12-18). As such, assuming independent multiplicative effects, in a population not receiving treatment, polypill one (aspirin, ACE-inhibitor, thiazide-type diuretic, and at statin for primary prevention) is projected to reduce the incidence of CHD and stroke by $62 \%$ and $59 \%$, respectively, and polypill two (aspirin, ACE-inhibitor, beta-blocker, and a statin for secondary prevention) is projected to reduce the incidence of CHD and stroke by $61 \%$ and $59 \%$, respectively.

Projected side effects with polypill use-The rates (95\% CI) of side effects from aspirin, thiazide-type diuretics, ACE-inhibitors, beta-blockers and statins have been reported to be $3.9 \%(2.2 \%, 5.6 \%), 9.9 \%(6.6 \%, 13.2 \%), 3.9 \%$ (-0.5\%, $8.3 \%), 7.5 \%(4.0 \%, 10.9 \%)$, and $0.1 \%(-1 \%, 1 \%)$, respectively $(2 ; 19 ; 20)$. Assuming independent additive effects, polypills one and two are estimated to result in side-effects in $17.8 \%$ and $15.4 \%$ of its users, respectively.

Individuals already taking components of the polypills (e.g., statins) were projected to experience only the risk reduction benefit and side effect disadvantage from the polypill ingredients that they were not already taking.

Incidence rates of coronary heart disease-CHD and stroke incidence rates for all adults $\geq 55$ years of age and individuals with a history of CVD, separately, were determined by pooling individual-level data from limited-access databases for three prospective population-based cohort studies: the Framingham Offspring Study, the Atherosclerosis Risk in Communities Study (ARIC), and the Cardiovascular Health Study (CHS)(21-23). In the pooled data set used for analysis, there were 14,568 adults $\geq 55$ years of age and 3,104 adults with a history of CVD. Event data in the public-access datasets are limited to 9 years of follow-up. Ten-year event rates were calculated by multiplying the 9 year event rates by 10 and dividing this product by 9 . Protocols were approved by the relevant institutional review boards and informed consent was obtained from all study participants. 


\section{Statistical Analysis}

Two parallel analyses were performed, one for each set of polypill eligibility criteria (i.e., [1] the general population approach of US adults $\geq 55$ years of age and [2] restricted to individuals with a history of CVD). Using NHANES 2007-2008, the number and characteristics of US adults eligible for polypills was calculated. The percentages of polypill-eligible US adults recommended aspirin, antihypertensive medications and statins under current treatment guidelines were calculated. Additionally, the percentage of those recommended each therapy who was actually taking it was calculated.

The 10-year incidence rates of CHD and stroke was calculated for adults $\geq 55$ years of age and individuals with a history of CVD using data from the pooled Framingham Offspring Study, ARIC Study, and CHS cohort databases. The number of CHD and stroke events expected to occur over the next 10 years among US adults was calculated as the product of these incidence rates and the number of US adults $\geq 55$ years and the number of US adults with a history of CVD, according to NHANES 2007-2008. The percent and number of CHD and stroke events potentially saved, over 10 years, simulating polypill use, was projected by applying the risk reduction rates from meta-analyses to the expected number of CHD and stroke events among the population eligible for polypill use. An identical approach was taken to estimate the number of side effects caused by polypill use. Sensitivity analyses were conducted by calculating the risk reduction and side effects projections of the two polypills using the lower (worst case) and upper bounds (best case) of the confidence intervals from the meta-analyses. Also, as individuals not currently taking antihypertensive medications or statins may not take a polypill, a separate sensitivity analysis was conducted to assess the reduction in CHD and stroke incidence and side effects, assuming that only individuals already taking at least one of these medications would take a polypill. Finally, as the benefit of polypill medications may not be multiplicative when combined, we also projected the benefits of polypills using a sub-multiplicative model wherein each medication was assumed to have $80 \%$ of its effects estimated from the meta-analyses. Under these assumptions, in a population naïve to all polypill medications, polypill one is projected to potentially reduce the incidence of CHD and stroke by 55\% and 50\%, respectively, and polypill two is projected to potentially reduce the incidence of CHD and stroke by $50 \%$ and $51 \%$, respectively.

SUDAAN (version 9.1, Research Triangle Park, NC) was used for all NHANES analyses to account for its complex sampling design. SAS (version 9.2, Cary, NC) was used for the analysis of the pooled cohort data.

This research was, in part, funded through a grant from the National Institutes of Health. The authors are solely responsible for the design and conduct of this study, all study analyses, the drafting and editing of the paper and its final contents.

\section{Results}

\section{Polypill-eligible population}

Using the criteria of all US adults $\geq 55$ years of age and those with a history of CVD, there are 67.6 and 15.4 million US adults eligible for a polypill, respectively. Table 1 presents the demographic characteristics and levels and prevalence of CVD risk factors for these two populations.

\section{Current medication use}

Under current guidelines, $84.2 \%$ of US adults $\geq 55$ years of age and all individuals with a history of CVD are recommended aspirin (Table 2). Due to the presence of hypertension and 
high cholesterol, a majority of these two populations are recommended antihypertensive medications and statins. However, among US adults $\geq 55$ years of age who are recommended each treatment, only $37.5 \%, 79.5 \%$, and $58.6 \%$ were taking aspirin, antihypertensive medications and statins, respectively. Among those with a history of CVD, uptake rates of aspirin, antihypertensive medications and statins were $44.5 \%, 87.8 \%$, and $64.6 \%$, respectively. Additionally, among US adults with a history of myocardial infarction, $54.1 \%$ were taking beta-blockers.

\section{CHD risk reduction}

The 10 year incidence of CHD and stroke events in the pooled Framingham Offspring Study, ARIC study, CHS cohorts were $10.7 \%$ and $6.7 \%$, respectively, for adults $\geq 55$ years of age and $18.3 \%$ and $10.6 \%$, respectively, for participants with a history of CVD (Figure 1, top panels). After accounting for current medication use, it is projected that polypill use among all US adults $\geq 55$ years of age would potentially reduce the 10 year incidence of CHD and stroke by $44 \%$ and $37 \%$, respectively. The equivalent potential CHD and stroke risk reductions for those with a history of CVD would be $32 \%$ and $30 \%$, respectively. Over 10 years of follow-up, polypill use is projected to potentially result in 3.2 and 1.7 million fewer CHD and stroke events, respectively, among US adults $\geq 55$ years of age, and 0.9 and 0.5 million fewer CHD and stroke events, respectively, for US adults with a history of CVD (Figure 1, bottom panels).

\section{Side Effects}

If polypills were taken by all US adults $\geq 55$ years of age, adverse side effects are projected to occur in $9.9 \%$ of users. The corresponding percentage for polypill use by US adults with a history of CVD is $6.7 \%$.

\section{Sensitivity Analyses}

Modeling the lower bound of risk benefits (i.e., the lower end of the expected risk reductions from the meta-analyses), polypill use is projected to result in $18 \%$ and $23 \%$ reductions in CHD and stroke, respectively, among US adults $\geq 55$ years of age and $20 \%$ and $14 \%$ risk reductions, respectively, for those with a history of CVD (Table 3). Modeling the upper limits of benefits resulted in projected 58\% and $48 \%$ reductions in CHD and stroke, respectively, among US adults $\geq 55$ years of age and $38 \%$ and $42 \%$ risk reductions, respectively, for US adults with a history of CVD. Using the lower bound, side effects are projected to occur in $5.0 \%$ and $2.8 \%$ of US adults $\geq 55$ years of age and with a history of CVD, respectively. Modeling the upper bounds, side effects are projected for $15.7 \%$ and $11.0 \%$ of these groups, respectively.

If only individuals currently taking an antihypertensive medication or a statin were to take a polypill, the 10 year incidence of CHD and stroke would be reduced by $27 \%$ and $22 \%$, respectively, among US adults $\geq 55$ years of age and by $25 \%$ and $24 \%$, respectively, among US adults with a history of CVD (Table 4). Use of polypills by individuals currently taking at least one medication contained in the poylpill is projected to potentially prevent 2.4 and 1.1 million CHD and stroke events, respectively, among US adults $\geq 55$ years of age and 1.4 and 0.7 million CHD and stroke events, respectively, among US adults with a history of CVD.

In a final sensitivity analysis, the potential CHD and stroke prevention benefits were calculated assuming each polypill medication had a sub-multiplicative effect of $80 \%$ efficacy. Under this assumption, the use of polypills may potentially prevent 2.6 and 1.4 million CHD and stroke events, respectively, among US adults $\geq 55$ years of age and 0.7 
and 0.4 million CHD and stroke events, respectively, among US adults with a history of CVD.

\section{Discussion}

The current study suggests that cardiovascular risk reduction medications are under-utilized among US adults. Even among the 15.4 million US adults with a history of CVD, fewer than $60 \%$ are taking aspirin and beta-blockers. We project that the population-wide use of polypills containing aspirin, a thiazide-type diuretic, an ACE-inhibitor and a statin among all US adults $\geq 55$ years of age has the potential to prevent millions of CHD and stroke events over the next 10 years. The potential for substantial risk reduction was also present when polypills were considered only for US adults with a history of CVD.

Results from a recent randomized controlled trial indicated a polypill containing aspirin, simvastatin, atenolol, ramipril and a thiazide diuretic improved individuals' cardiovascular risk profile $(24 ; 25)$. In this trial, the polypill provided a similar degree of lowering blood pressure and heart rate lowering effects when compared to its individuals antihypertensive components. Additionally, the polypill resulted in a significant lowering of LDL-cholesterol and urinary 11-dehydrothromboxane B2, compared to placebo. However, the effect in those randomized to the polypill was less than their counterparts randomized to simvastatin (27 versus $32 \mathrm{mg} / \mathrm{dL}$ ) and aspirin ( 283.1 versus $350.0 \mathrm{ng} / \mathrm{mmol}$ creatinine). Thus, the authors concluded that the polypill being tested may not provide the benefits expected based on the multiplicative effects of its individual components. Despite this caveat, based on the reductions experienced for individuals randomized to receive this polypill $(7.4 \mathrm{mmHg}$ reduction in systolic blood pressure, $27 \mathrm{mg} / \mathrm{dL}$ reduction in LDL-cholesterol and 283.1 reduction in $\mathrm{ng} / \mathrm{mmol}$ creatinine 11-dehydrothromboxane B2), a substantial reduction in CVD risk could be expected. In fact, in a sensitivity analysis assuming $20 \%$ lesser reductions in events than expected from use of individual polypill medications, we project that millions of CHD and stroke events may still be prevented over a 10 year period.

Prior epidemiological analyses have investigated the potential benefits of polypills. For example, a study by Gaziano and colleagues reported a multi-drug primary prevention strategy of treating patients from low and middle income countries with a 10 -year absolute risk of cardiovascular disease of more than 5\% may result in reductions of $42 \%$ to $57 \%$ in lifetime risk of death from cardiovascular disease(26). Additionally, a report "Assessing Cost-Effectiveness in Prevention" from Australia detailed a potential for 230,000 disabilityadjusted life years gained through population-wide polypill use(27). The polypill was also found to result in cost-savings.

While the projected potential benefits of polypills as estimated in the current study are compelling, Lonn and colleagues recently described several reservations regarding the polypill that need to be addressed prior to fully advocating their broad adoption (11). Importantly, data are still needed from randomized controlled trials on the benefits of polypills in preventing CHD and strokes. Additional items cited include determining the ideal pharmaceutical formulation of polypills, polypill adherence issues, the abandonment of healthy lifestyles by patients taking polypills, and the acceptability of taking additional medications by the population at large. Caution is warranted until data become available to address these uncertainties.

The expected benefits of wide-spread polypill use must be balanced by the projected occurrence of new adverse side effects in up to $17 \%$ of its users. However, these will not tend to be severe (e.g., cough, dizziness, nausea, and abdominal discomfort). While more severe side effects (e.g., bleeding, angioedema) do occur with the use of the polypill drugs, 
these are unlikely to occur frequently. However, such side effects may also limit the beneficial effects of polypill use.

Cardio-protective medications are under-utilized among US adults. The reasons why patients do not take these medications are varied and include their beliefs about pharmacologic medications, side effects, and lack of access to healthcare(28). Incorporating aspirin, antihypertensive medications and statins into a single pill is widely predicted to improve medication use and adherence(29). Several studies suggest that complex medication taking regimens are an important barrier to achieving high medication adherence among patients with hypertension and high cholesterol. The use of polypills has the potential to make medication-taking regimens simpler, likely resulting in improved medication adherence and possibly reduced CVD incidence.

The current study has potential limitations. For example, we relied on projections to estimate the CHD and stroke risk reduction associated with polypill use. Additionally, while risk reduction benefits and side effects are based on published data from randomized trials, 10 years of follow-up for the benefits and side effects were not available. Data are not currently available on the risk reduction benefits of polypills and, thus, the potential benefits relied on previously published meta-analyses. NHANES 2007-2008 provides nationally representative estimates for the civilian non-institutionalized US population but it does not have data on CHD and stroke incidence. Therefore, we used data from three large cohort studies. Although these cohorts are population-based and maintain active follow-up and adjudication of incident fatal and non-fatal CVD events, they are not based upon nationally representative samples.

Several polypills aimed at CVD reduction are currently under development and being evaluated in randomized controlled trials. While the CVD risk reduction benefits of polypills still need to be determined in randomized controlled trials, the use of polypills among US adults at high risk for CVD has the potential to prevent millions of CHD and stroke events.

\section{Reference List}

1. World Health Organization. WHO-Wellcome Trust meeting report 1-3. Geneva: 2002. Secondary prevention of non-communicable disease in low and middle income countries through communitybased and health service interventions.

2. Wald NJ, Law MR. A strategy to reduce cardiovascular disease by more than $80 \%$. BMJ. 2003; 326(7404):1419. [PubMed: 12829553]

3. Rodgers A. A cure for cardiovascular disease? Combination treatment has enormous potential, especially in developing countries. BMJ. 2003; 326(7404):1407-1408. [PubMed: 12829526]

4. Watts G. What happened to the polypill? BMJ. 2008; 337:a1822. [PubMed: 18819953]

5. Fuster V, Sanz G. A polypill for secondary prevention: time to move from intellectual debate to action. Nat Clin Pract Cardiovasc Med. 2007; 4(4):173. [PubMed: 17380163]

6. National Center for Health Statistics. NHANES Design and Conduct. 2008. http://www.cdcgov/nchs/about/major/nhanes/

7. Perloff D, Grim CE, Flack JM, Frohlich ED, Hill M, McDonald M, et al. Human blood pressure determination by sphygmomanometry. Circulation. 1993; 88:2460-2470. [PubMed: 8222141]

8. Executive Summary of The Third Report of The National Cholesterol Education Program (NCEP) Expert Panel on Detection, Evaluation, And Treatment of High Blood Cholesterol In Adults (Adult Treatment Panel III). JAMA. 2001; 285(19):2486-2497. [PubMed: 11368702]

9. Mosca L. Aspirin chemoprevention: one size does not fit all. Circulation. 2008; 117(22):2844-2846. [PubMed: 18519859]

10. Smith SC Jr, Allen J, Blair SN, Bonow RO, Brass LM, Fonarow GC, et al. AHA/ACC guidelines for secondary prevention for patients with coronary and other atherosclerotic vascular disease: 
2006 update: endorsed by the National Heart, Lung, and Blood Institute. Circulation. 2006; 113(19):2363-2372. [PubMed: 16702489]

11. Lonn E, Bosch J, Teo KK, Pais P, Xavier D, Yusuf S. The polypill in the prevention of cardiovascular diseases: key concepts, current status, challenges, and future directions. Circulation. 2010; 122(20):2078-2088. [PubMed: 21098469]

12. Psaty BM, Lumley T, Furberg CD, Schellenbaum G, Pahor M, Alderman MH, et al. Health outcomes associated with various antihypertensive therapies used as first-line agents: a network meta-analysis. JAMA. 2003; 289(19):2534-2544. [PubMed: 12759325]

13. Baigent C, Blackwell L, Collins R, Emberson J, Godwin J, Peto R, et al. Aspirin in the primary and secondary prevention of vascular disease: collaborative meta-analysis of individual participant data from randomised trials. Lancet. 2009; 373(9678):1849-1860. [PubMed: 19482214]

14. O'Regan C, Wu P, Arora P, Perri D, Mills EJ. Statin therapy in stroke prevention: a meta-analysis involving 121,000 patients. Am J Med. 2008; 121(1):24-33. [PubMed: 18187070]

15. Ward S, Lloyd JM, Pandor A, Holmes M, Ara R, Ryan A, et al. A systematic review and economic evaluation of statins for the prevention of coronary events. Health Technol Assess. 2007; 11(14): $1-$ iv.

16. Bradley HA, Wiysonge CS, Volmink JA, Mayosi BM, Opie LH. How strong is the evidence for use of beta-blockers as first-line therapy for hypertension? Systematic review and meta-analysis. J Hypertens. 2006; 24(11):2131-2141. [PubMed: 17053529]

17. Wiysonge CS, Bradley H, Mayosi BM, Maroney R, Mbewu A, Opie LH, et al. Beta-blockers for hypertension. Cochrane Database Syst Rev. 2007; (1):CD002003. [PubMed: 17253471]

18. Neal B, MacMahon S, Chapman N. Effects of ACE inhibitors, calcium antagonists, and other blood- pressure-lowering drugs: results of prospectively designed overviews of randomised trials. Blood Pressure Lowering Treatment Trialists' Collaboration. Lancet. 2000; 356(9246):1955-1964. [PubMed: 11130523]

19. Law MR, Wald NJ, Morris JK, Jordan RE. Value of low dose combination treatment with blood pressure lowering drugs: analysis of 354 randomised trials. BMJ. 2003; 326(7404):1427. [PubMed: 12829555]

20. Law MR, Wald NJ, Rudnicka AR. Quantifying effect of statins on low density lipoprotein cholesterol, ischaemic heart disease, and stroke: systematic review and meta-analysis. BMJ. 2003; 326(7404):1423. [PubMed: 12829554]

21. Kannel WB, Feinleib M, McNamara PM, Garrison RJ, Castelli WP. An investigation of coronary heart disease in families. The Framingham offspring study. Am J Epidemiol. 1979; 110(3):281290. [PubMed: 474565]

22. The ARIC Study Investigators. The decline of ischaemic heart disease mortality in the ARIC study communities. International Journal of Epidemiology. 1989; 18(3):S88-S98. [PubMed: 2681023]

23. Fried LP, Borhani NO, Enright P, Furberg CD, Gardin JM, Kronmal RA, et al. The Cardiovascular Health Study: design and rationale. Ann Epidemiol. 1991; 1(3):263-276. [PubMed: 1669507]

24. Yusuf S, Pais P, Afzal R, Xavier D, Teo K, Eikelboom J, et al. Effects of a polypill (Polycap) on risk factors in middle-aged individuals without cardiovascular disease (TIPS): a phase II, doubleblind, randomised trial. Lancet. 2009; 373(9672):1341-1351. [PubMed: 19339045]

25. Patel A, Shah T, Shah G, Jha V, Ghosh C, Desai J, et al. Preservation of bioavailability of ingredients and lack of drug-drug interactions in a novel five-ingredient polypill (polycap): a fivearm phase I crossover trial in healthy volunteers. Am J Cardiovasc Drugs. 2010; 10(2):95-103. [PubMed: 20334446]

26. Gaziano TA, Opie LH, Weinstein MC. Cardiovascular disease prevention with a multidrug regimen in the developing world: a cost-effectiveness analysis. Lancet. 2006; 368(9536):679-686. [PubMed: 16920473]

27. Vos, T.; Carter, R.; Barendregt, J.; Mihalopoulos, C.; Veerman, JL.; Magnus, A., et al. Assessing Cost-Effectiveness in Prevention (ACE-Prevention): Final Report. University of Queensland, Brisbane and Deakin University; Melbourne: 2010.

28. Ogedegbe G, Harrison M, Robbins L, Mancuso CA, Allegrante JP. Barriers and facilitators of medication adherence in hypertensive African Americans: a qualitative study. Ethn Dis. 2004; 14(1):3-12. [PubMed: 15002917] 
29. Haynes RB, McDonald HP, Garg AX. Helping patients follow prescribed treatment: clinical applications. JAMA. 2002; 288(22):2880-2883. [PubMed: 12472330] 


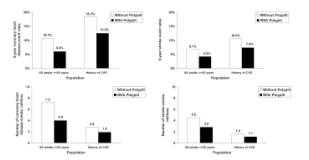

Figure 1.

Percentage (top panel) and number (bottom panel) of US adults expected to have a coronary heart disease event (left panels) or stroke (right panels) over the next 10 years with and without us e of polypills.

History of cardiovascular disease (CVD) Includes individuals with a history of myocardial infarction, coronary heart disease, or stroke

Without Polypill - Numbers are the product of the population size, estimated from NHANES 1999-2004, times the 10-year coronary heart disease incidence rates estimated using participants in the population-based Framingham Offspring Study, Atherosclerosis Risk in Communities study (ARIC) and the Cardiovascular Health Study (CHS) meeting the listed criteria.

With Polypill - Calculated as the observed coronary heart disease and stroke event rates in the Framingham Offspring Study, ARIC and CHS multiplied by the event reductions associated with the polypill medications as described in the methods section. 
Table 1

Characteristics of US adults $\geq 55$ years of age and those with a history of cardiovascular disease.

\begin{tabular}{|l|c|c|}
\hline & $\begin{array}{c}\text { US adults } \mathbf{2 5 5} \text { years } \\
(\mathbf{n = 2 5 5 4})\end{array}$ & $\begin{array}{c}\text { History of Cardiovascular Disease } \\
(\mathbf{n = 5 9 2})\end{array}$ \\
\hline Mean (SD) age, years & $66.9(0.3)$ & $65.1(0.8)$ \\
\hline Male sex, \% & $43.9 \%$ & $54.7 \%$ \\
\hline Race-ethnicity & & $75.8 \%$ \\
\hline Non-Hispanic white, \% & $78.0 \%$ & $11.6 \%$ \\
\hline Non-Hispanic black, \% & $9.6 \%$ & $6.8 \%$ \\
\hline Mexican-American, \% & $7.7 \%$ & $21.7 \%$ \\
\hline Cigarette smoking, $\%$ & $12.7 \%$ & $130.3(1.1)$ \\
\hline Mean (SD) systolic BP, mmHg & $131.5(0.7)$ & $68.1(1.1)$ \\
\hline Mean (SD) diastolic BP, $\mathrm{mmHg}$ & $68.9(0.6)$ & $69.3 \%$ \\
\hline Hypertension, $\%$ & $60.1 \%$ & $49.3(0.6)$ \\
\hline Mean (SD) HDL-cholesterol, $\mathrm{mg} / \mathrm{dL}$ & $53.8(0.6)$ & $102.9(3.1)$ \\
\hline Mean (SD) LDL-cholesterol, $\mathrm{mg} / \mathrm{dL}$ & $116.5(1.9)$ & $88.3 \%$ \\
\hline High LDL-cholesterol, \% & $63.7 \%$ & $15.6 \%$ \\
\hline Diabetes mellitus, $\%$ & $10.3 \%$ & $46.0 \%$ \\
\hline History of myocardial infarction, $\%$ & $8.2 \%$ & $45.5 \%$ \\
\hline History of coronary heart disease, $\%$ & $8.7 \%$ & $20.9 \%$ \\
\hline Angina, \% & $5.3 \%$ & $44.1 \%$ \\
\hline History of stroke, $\%$ & $7.4 \%$ & \\
\hline
\end{tabular}

Abbreviations: SD - standard deviation; BP - blood pressure.

$\mathrm{n}$ represents number of participants in NHANES 2007-2008.

${ }^{\dagger}$ Includes a history of myocardial infarction, coronary heart disease, or stroke.

LDL-cholesterol is based on 977 participants $\geq 55$ years and 240 participants with a history of cardiovascular disease and fasting samples. 


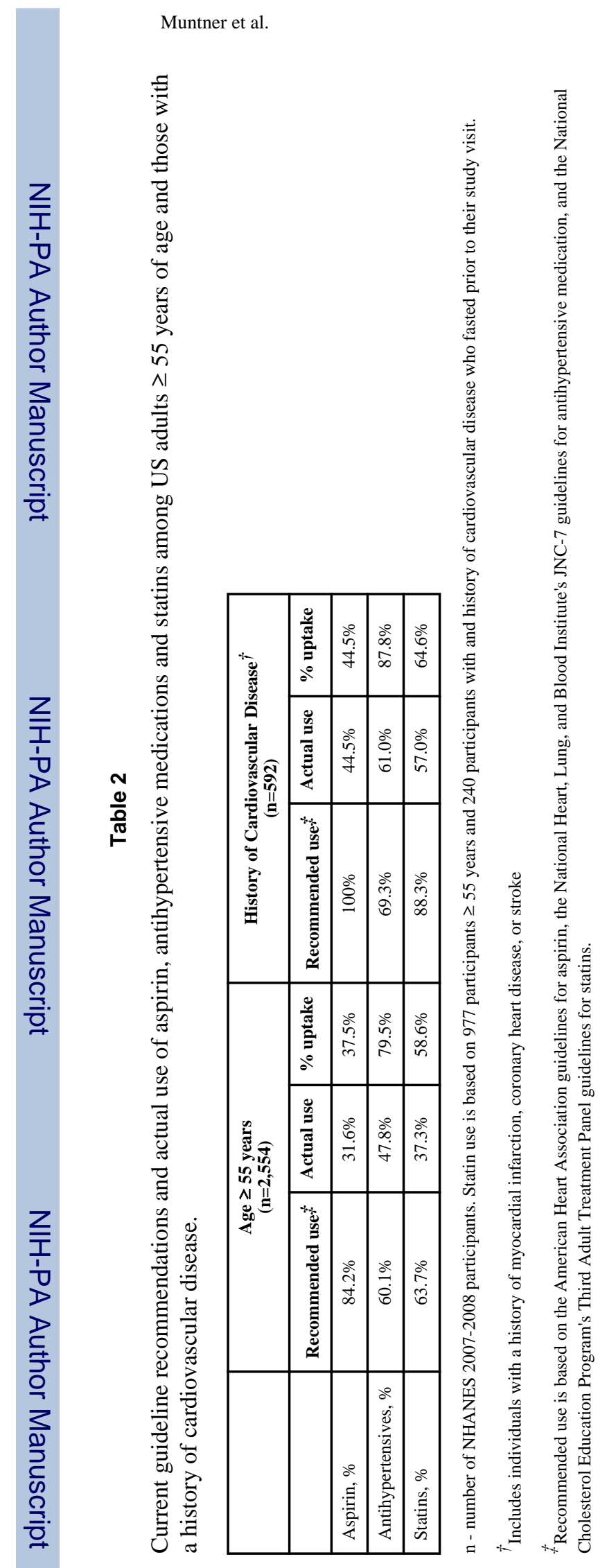

Am Heart J. Author manuscript; available in PMC 2012 April 1. 


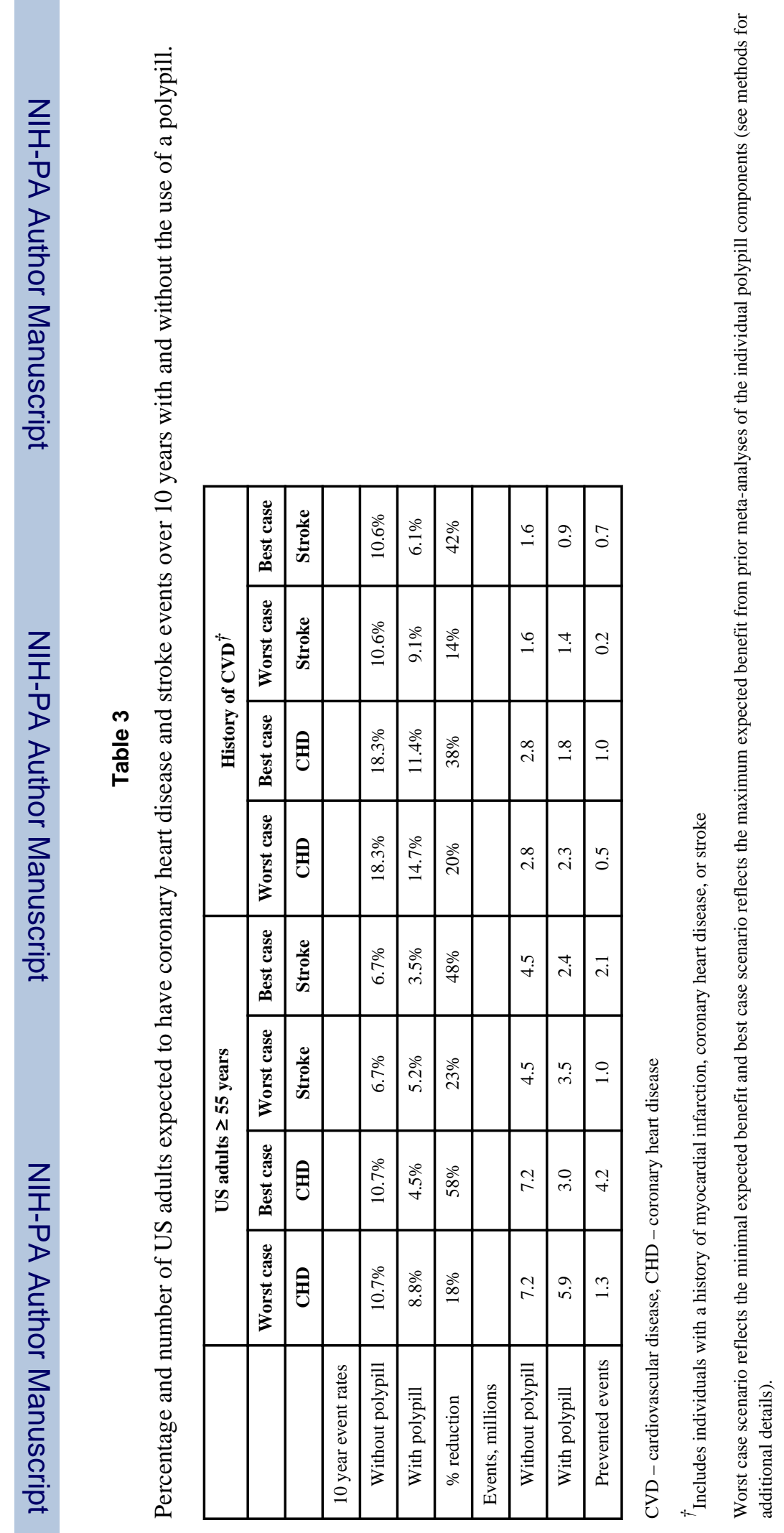

Am Heart J. Author manuscript; available in PMC 2012 April 1. 
Table 4

Sensitivity analyses showing the percentage and number of US adults expected to have coronary heart disease and stroke events over 10 years with and without the use of a polypill assuming only persons currently antihypertensive medications or statins will take the polypill.

\begin{tabular}{|l|c|c|c|c|}
\hline & US adults $\geq \mathbf{5 5}$ years & \multicolumn{2}{|c|}{ History of CVD } \\
\hline Number of US adults, millions & \multicolumn{2}{|c|}{67.6} & \multicolumn{2}{|c|}{15.4} \\
\hline Number on antihypertensive or statin medication, millions & \multicolumn{2}{|c|}{41.8} & \multicolumn{2}{c|}{12.0} \\
\hline & CHD & Stroke & CHD & Stroke \\
\hline 10 -year event rates & & & & \\
\hline Without polypill & $10.7 \%$ & $6.7 \%$ & $18.3 \%$ & $10.6 \%$ \\
\hline With polypill & $7.8 \%$ & $5.2 \%$ & $13.8 \%$ & $8.1 \%$ \\
\hline$\%$ reduction & $27 \%$ & $22 \%$ & $25 \%$ & $24 \%$ \\
\hline Events, millions & & & & \\
\hline Without polypill & 7.2 & 4.5 & 2.8 & 1.6 \\
\hline With polypill & 5.3 & 3.5 & 2.1 & 1.2 \\
\hline Prevented events & 1.9 & 1.0 & 0.7 & 0.4 \\
\hline
\end{tabular}

CVD - cardiovascular disease, CHD - coronary heart disease

${ }^{\dagger}$ Includes individuals with a history of myocardial infarction, coronary heart disease, or stroke 